\title{
Promoção a saúde em uma clínica pediátrica: vivências de estudantes de enfermagem
}

\author{
Health promotion in a pediatric clinic: experiences of nursing students \\ Promoción de la salud en una clínica pediátrica: experiencias de estudiantes de enfermeira
}

Recebido: 26/02/2021 | Revisado: 07/03/2021 | Aceito: 25/09/2021 | Publicado: 27/09/2021

Tatiane de Sousa Paiva

ORCID: https://orcid.org/0000-0001-8555-6355 Universidade Estadual Vale do Acaraú, Brasil E-mail: tatianesousa503@gmail.com

Natasha Vasconcelos Sobrinho ORCID: https://orcid.org/0000-0003-3605-8602 Universidade Estadual Vale do Acaraú, Brasil E-mail:natashavascon2206@hotmail.com

Thamires Sales Macêdo

ORCID: https://orcid.org/0000-0002-3896-0184 Universidade Estadual Vale do Acaraú, Brasil

E-mail: thamiressales1998@outlook.com

Maria Idelânia Alves da Silva

ORCID: https://orcid.org/0000-0002-9069-0396

Universidade Estadual Vale do Acaraú, Brasil

E-mail: mariaidelania@outlook.com

Maria Pereira Cassimiro

ORCID: https://orcid.org/0000-0002-1683-1533

Universidade Estadual Vale do Acaraú, Brasil

E-mail: maria_p_cassimiro@hotmail.com

Ingrid Kelly Morais Oliveira

ORCID: https://orcid.org/0000-0003-1536-7289

Universidade Estadual Vale do Acaraú, Brasil

E-mail: ingridkelly17.ik@gmail.com

Luís Henrique Azevedo Moreira

ORCID: https://orcid.org/0000-0003-3803-0259 Universidade Estadual Vale do Acaraú, Brasil

E-mail: luishenriqueazevedosh@ gmail.com

Maria Adelane Monteiro da Silva

ORCID: https://orcid.org/0000-0001-7579-2645

Universidade Estadual Vale do Acaraú, Brasil

E-mail: adelanemonteiro@ @otmail.com

Francisca Isaelly dos Santos Dias

ORCID: https://orcid.org/0000-0002-6420-4382 Universidade Federal do Ceará, Brasil

E-mail: isaellydias@hotmail.com

Cibelly Aliny Siqueira Lima Freitas

ORCID: https://orcid.org/0000-0002-0585-5345

Universidade Estadual Vale do Acaraú, Brasil E-mail: cibellyaliny@gmail.com

\begin{abstract}
Resumo
Descrever a experiência de cuidado vivenciada com crianças hospitalizadas a partir da ludoterapia. Trata-se de um estudo descritivo do tipo relato de experiência, desenvolvido a partir das vivências de discentes de enfermagem, permeada pelas atividades do Módulo de Práticas Interdisciplinares em Ensino, Pesquisa e Extensão II - PIEPE II, do Curso de Enfermagem da Universidade Estadual Vale do Acaraú - UVA. Foram realizadas no período de maio a julho de 2019, na pediatria do Hospital Santa Casa de Misericórdia, localizado no município de Sobral, estado do Ceará. As intervenções executadas foram realizadas em sete encontros e na aplicação das intervenções, cada acadêmica construiu um personagem diferente para se apresentarem nas ações e abordar os temas de forma lúdica. O resultado das intervenções foi avaliado de acordo com a interação e o entusiasmo das crianças durante as dinâmicas. Para dar início ao processo de intervenções, as acadêmicas fizeram uma visita prévia ao Setor de Pediatria para ver a realidade situacional das crianças. Diante disso, nota-se que a ludoterapia apresentaram-se satisfatória, pois favoreceram uma comunicação efetiva, a formação de vínculo entre profissional-paciente e possibilitou o cuidado integral e humanizado. A vivência proporcionou uma visão além da teoria, agregando valores na formação acadêmica sobre a relevância da assistência holística e humanizada que deve ser trabalhada com o paciente, em especial o infantil.
\end{abstract}

Palavras-chave: Promoção em saúde; Enfermagem; Criança. 


\begin{abstract}
Describe the care experience lived with hospitalized children from play therapy. This is a descriptive study of the experience report type, developed from the experiences of nursing students, permeated by the activities of the Module of Interdisciplinary Practices in Teaching, Research and Extension II - PIEPE II, of the Nursing Course at Universidade Estadual Vale do Acaraú - UVA. They were carried out from May to July 2019, in the pediatrics of Hospital Santa Casa de Misericórdia, located in the municipality of Sobral, state of Ceará. The performed interventions were carried out in seven meetings and in the application of the interventions, each academic built a different character to present themselves in the actions and approach the themes in a playful way. The result of the interventions was evaluated according to the interaction and enthusiasm of the children during the dynamics. To start the process of interventions, the academics made a previous visit to the Pediatrics Sector to see the children's situational reality. In view of this, it is noted that play therapy was satisfactory, as it favored effective communication, the formation of a bond between professional-patient and enabled comprehensive and humanized care. The experience provided a view beyond theory, adding values in academic training on the relevance of holistic and humanized care that must be worked with the patient, especially the child.
\end{abstract}

Keywords: Health promotion; Nursing; Kid.

\title{
Resumen
}

Describe la experiencia de cuidado vivida con niños hospitalizados por terapia de juego. Se trata de un estudio descriptivo del tipo relato de experiencia, desarrollado a partir de las vivencias de estudiantes de enfermería, permeado por las actividades del Módulo de Prácticas Interdisciplinarias en Docencia, Investigación y Extensión II PIEPE II, del Curso de Enfermería de la Universidad Estadual Vale do Acaraú - UVA. Se llevaron a cabo de mayo a julio de 2019, en la pediatría del Hospital Santa Casa de Misericórdia, ubicado en el municipio de Sobral, estado de Ceará. Las intervenciones realizadas se llevaron a cabo en siete encuentros y en la aplicación de las intervenciones, cada académico construyó un personaje diferente para presentarse en las acciones y abordar los temas de manera lúdica. El resultado de las intervenciones se evaluó de acuerdo a la interacción y entusiasmo de los niños durante la dinámica. Para iniciar el proceso de intervenciones, los académicos realizaron una visita previa al Sector de Pediatría para ver la realidad situacional de los niños. Ante esto, se constata que la terapia lúdica resultó satisfactoria, ya que favoreció la comunicación efectiva, la formación de un vínculo entre profesional-paciente y posibilitó una atención integral y humanizada. La experiencia brindó una mirada más allá de la teoría, agregando valores en la formación académica sobre la relevancia del cuidado integral y humanizado que se debe trabajar con el paciente, especialmente el niño.

Palabras clave: Promoción de la salud; Enfermería; Niño.

\section{Introdução}

A infância normalmente trata-se de uma fase intensa no desenvolvimento humano, psicomotor e social, no entanto o processo de adoecimento causa na criança sensações estressantes e temerosas. Estas quando associadas a hospitalização representam um evento hostil e incomum a sua rotina, pois é submetida a procedimentos hospitalares e tratamentos terapêuticos que podem acarretar dor, sofrimento físico e psicológico (Meira et. al, 2017).

Além da sua inserção em outra realidade em um ambiente impessoal, repleto de restrições e rotinas, com significados diferentes do seu contexto diário e longe de seus familiares e amigos, a criança necessita receber assistência adequada e com ausência de traumas para sua recuperação, a fim de minimizar o estresse gerado pela hospitalização. Logo, uma boa comunicação e interação para o cuidado adequado e seguro, entre pacientes, familiares e a equipe de saúde durante o processo de hospitalização se faz necessária (Azevedo et. al, 2017).

Muitas ações e métodos de humanização da assistência hospitalar têm sido adotados pelo mundo, mais do que humanizar o atendimento visam melhorar as relações entre profissionais da saúde e pacientes (Oliveira, 2016). Essas estratégias buscam resgatar valores como solidariedade, colaboração, afetividade nas relações, respeito à diversidade, valorização das queixas, educação continuada e cuidado com o outro (Catapan; Oliveira \& Rotta, 2019).

Dessa forma, ao utilizar o "brincar" como recurso terapêutico auxilia na melhor compreensão e aceitação do tratamento, proporcionando uma recuperação menos dolorosa, ao favorecer o enfrentamento da enfermidade. Além de promover o estreitamento de vínculos entre o profissional de saúde e o paciente, caracterizando-se como elementos indispensáveis para a melhoria na qualidade da atenção no campo da enfermagem pediátrica (Berté et. al, 2017). 
Foi possível notar, em estudos recentes, vantagens positivas da imersão do lúdico com público infantil durante sua permanência no ambiente hospitalar, sendo esta uma metodologia alternativa para a melhoria do estado emocional bem aceita pelos pacientes. Foi observado também que as atividades lúdicas e a presença da família podem beneficiar a compreensão da criança sobre a sua hospitalização (Silva et. al, 2017).

Em concordância com esse fato, a interação baseada na brincadeira entre os pacientes e profissionais da saúde permitiu que eles verbalizassem acerca das percepções dos medos enfrentados durante a sua internação, mostrando-se um canal de verbalização, interação e fortalecimento de vínculo, favorecendo a participação da criança no seu cuidado. Além disso, favoreceu maior receptividade dessas crianças à equipe de enfermagem, bem como a novos procedimentos que venham a ser realizados durante a internação (Barroso et. al, 2020).

Desta forma, considerando que a equipe de enfermagem também é responsável pelo processo de alívio da dor física e psíquica, utilizando recursos terapêuticos não farmacológicos, como a musicoterapia, arte terapia e demais metodologias lúdicas, amenizando o sofrimento e proporcionando momentos felizes para as crianças, torna-se relevante o estudo sobre a utilização da ludoterapia na assistência à criança hospitalizada.

Com base na literatura e com objetivo de aliviar o sofrimento físico e psíquico de crianças em processo de hospitalização, o presente estudo tem como justificativa a importância de trabalhar o cuidado, com vistas a minimizar o sofrimento físico e psíquico de pacientes pediátricos. A vista disso, este estudo tem por objetivo descrever a experiência de cuidado vivenciada com crianças hospitalizadas a partir da ludoterapia.

\section{Metodologia}

Trata-se de um estudo descritivo do tipo relato de experiência, este tipo de estudo exige do pesquisador diversas informações sobre o que deseja pesquisar, no qual pretende descrever os fatos e fenômenos de determinada realidade (Gerhardt, \& Silveira, 2009). Utilizou-se ainda uma abordagem qualitativa que, para Pereira et al. (2018), trata-se de um método no qual é importante a interpretação por parte do pesquisador com suas opiniões sobre o fenômeno em estudo. Desse modo, os produtos do estudo foram obtidos por meio de ações de promoção e educação em saúde com atividades lúdicas.

Este estudo foi desenvolvido a partir das vivências de discentes de enfermagem, permeada pelas atividades do Módulo de Práticas Interdisciplinares em Ensino, Pesquisa e Extensão II - PIEPE II, da matriz curricular do Curso de Enfermagem da Universidade Estadual Vale do Acaraú - UVA. Foram realizadas no período de maio a julho de 2019, nas dependências do setor de pediatria do Hospital Santa Casa de Misericórdia, localizado no município de Sobral, Estado do Ceará.

A pediatria da referida instituição possui 49 leitos, além de apartamentos com atendimentos particulares e convênios. Para melhor atender as necessidades das crianças, a unidade conta com uma equipe multiprofissional formada por médicos, enfermeiros, auxiliares, fisioterapeutas, assistentes sociais, terapia ocupacional e fonoaudiólogos (Santa Casa Misericórdia de Sobral-Ceará, 2012).

As intervenções propostas pelos acadêmicos foram baseadas nas necessidades encontradas na realidade do serviço, assim escolheu-se uma estratégia para cada intervenção, contendo: planejamento, intervenção propriamente dita e tendo como resultado a promoção da alegria e distração das crianças, fundamentadas nos pressupostos da educação em saúde. Essas atividades foram realizadas pelos acadêmicos por meio da metodologia lúdica com o auxílio da enfermeira de plantão, o que fortaleceu o vínculo com as crianças. Quando o lúdico permeia a assistência de Enfermagem, esta tende a facilitar a aceitação da criança quanto à realização de procedimentos dolorosos, pois essas atividades contribuem para tornar o ambiente hospitalar mais agradável proporcionando distração e lazer (Sabino, Esteves, Oliveira \& Silva, 2016). 
As temáticas abordadas tiveram como finalidade, propor momentos de descontração e diversão que proporcionasse conhecimento sobre assuntos relacionados aos riscos expostos para as crianças e seus acompanhantes, e também, gerar uma melhora na qualidade de vida durante a internação, propiciando um ambiente mais alegre e animado.

As intervenções executadas foram realizadas em sete encontros, primeiramente foram traçados os seguintes objetivos, respectivamente: conhecer o serviço, identificar os diagnósticos, traçar um plano de intervenção com a participação da equipe de enfermagem do setor e, por conseguinte, colocar em prática as atividades para promoção da saúde e bem-estar das crianças do setor.

No primeiro encontro junto com a enfermeira responsável pelo setor o serviço foi apresentado assim como as principais fragilidades que precisavam ser trabalhadas, a partir disto foram traçadas as intervenções pedagógicas, sendo elas: higiene e autocuidado, alimentação saudável, teatro sobre verminoses e contação de histórias, conhecendo o alfabeto, boas ações, prevenção de acidentes e a musicoterapia.

Durante o planejamento, quando o serviço foi conhecido, fez-se uma boa inspeção das necessidades das crianças, e foi constatado que, para que houvesse uma melhor participação das crianças nas atividades, as acompanhantes (mães) também deveriam ser incluídas e participar. Sendo assim, as intervenções se deram por meio de histórias e atividades lúdicas, o que possibilitou a promoção da saúde em cada temática estabelecida.

Para a aplicação das intervenções, cada acadêmica construiu um personagem diferente para se apresentarem nas ações e abordar o tema de forma lúdica, que foram: bailarina, princesa, coelha, ratinha e palhaça. Na intervenção propriamente dita, foram utilizados recursos materiais e criativos.

Desse modo, destaca-se que este estudo, por se constituir em um relato de experiência, não foi submetido à avaliação do Comitê de Ética em Pesquisa. No entanto, durante o seu desenvolvimento, pontua-se que foram considerados os preceitos éticos da Resolução n. ${ }^{\circ}$ 466/2012.

\section{Resultados}

O resultado das intervenções foi avaliado de acordo com a interação e o entusiasmo das crianças durante as dinâmicas. Para dar início ao processo de intervenções, as acadêmicas fizeram uma visita prévia ao Setor de Pediatria para ver a realidade situacional das crianças. Após a visita, tomaram os principais pontos de necessidade que foram vistos na primeira visita, e traçou-se um plano de cuidados proposto por intervenções. Ao todo, foram 7 ações, cada qual com uma temática diferente, com o objetivo de melhorar o processo de internação, bem como apoiar no desenvolvimento psicomotor e psicossocial da criança.

Isto posto, o Quadro 1 apresenta as ações desenvolvidas, descrevendo temática, objetivo, participantes e metodologia. 
Quadro 1 - Ações desenvolvidas, descrevendo temática, objetivo, participantes e metodologia. Sobral, Ceará, Brasil. 2020.

\begin{tabular}{|c|c|c|c|c|}
\hline Encontro & Temática & Objetivo & Participantes & Metodologia \\
\hline 1 & $\begin{array}{l}\text { Educação } \\
\text { em saúde: } \\
\text { higienização }\end{array}$ & $\begin{array}{l}\text { Enaltecer a } \\
\text { importância } \\
\text { de uma boa } \\
\text { higiene } \\
\text { corporal. }\end{array}$ & $\begin{array}{l}\text { Acadêmicas, pais } \mathrm{e} \\
\text { crianças. }\end{array}$ & $\begin{array}{l}\text { No primeiro momento foi colhido informações das crianças } \\
\text { a respeito de como elas faziam sua higienização, No } \\
\text { segundo momento foi enfatizado a importância de ter uma } \\
\text { boa higienização, enfatizando principalmente a importância } \\
\text { da escovação dos dentes, lavagem dos cabelos e lavagem } \\
\text { das mãos e para encerrar a ação foi cantado músicas de } \\
\text { passo-a-passo de como tomar banho e lavar as mão. }\end{array}$ \\
\hline 2 & $\begin{array}{l}\text { Promoção } \\
\text { da } \\
\text { alimentação } \\
\text { saudável }\end{array}$ & $\begin{array}{l}\text { Informar a } \\
\text { importância } \\
\text { de uma } \\
\text { alimentação } \\
\text { saudável } \\
\text { para o } \\
\text { crescimento } \\
\text { e } \\
\text { desenvolvi } \\
\text { mento } \\
\text { infantil. }\end{array}$ & $\begin{array}{l}\text { Acadêmicas, pais } \mathrm{e} \\
\text { crianças. }\end{array}$ & $\begin{array}{l}\text { Primeiramente foi realizada uma pergunta para os } \\
\text { acompanhantes das crianças, o que eles sabiam sobre os } \\
\text { alimentos: mamão, banana, goiaba, melancia, maçã, } \\
\text { laranja, feijão e leite. Eles responderam que basicamente } \\
\text { sabiam o básico e, logo então, eles receberam um papel } \\
\text { contendo informações sobre esses alimentos e a } \\
\text { importância da ingestão deles para o crescimento e } \\
\text { desenvolvimento saudável das crianças. Depois foi feito um } \\
\text { momento com as crianças onde foi abordado a mesma } \\
\text { temática e perguntando e informando os alimentos } \\
\text { importante, para aprimorar o aprendizado e compreensão, } \\
\text { foi entregue atividade lúdica de pintura para as crianças, na } \\
\text { qual continha imagens de frutas saudáveis e criança se } \\
\text { alimentando. }\end{array}$ \\
\hline 3 & $\begin{array}{l}\text { Jogo dos } \\
\text { sete erros: } \\
\text { riscos } \\
\text { domésticos } \\
\text { e riscos de } \\
\text { trânsito. }\end{array}$ & $\begin{array}{l}\text { Alertar aos } \\
\text { pais e as } \\
\text { crianças } \\
\text { sobre a } \\
\text { prevenção } \\
\text { de acidentes } \\
\text { domésticos } \\
\text { e acidentes } \\
\text { de trânsitos. }\end{array}$ & $\begin{array}{l}\text { Acadêmicas, pais } \mathrm{e} \\
\text { crianças. }\end{array}$ & $\begin{array}{l}\text { O jogo dos sete erros foi realizado de leito a leito onde, } \\
\text { cada criança visualizava alguma das ilustrações dos } 7 \text { erros } \\
\text { e falava o que estava errado, por exemplo: havia uma } \\
\text { ilustração que demonstrava uma cozinha com um cabo da } \\
\text { panela que estava com água fervendo não deve está para } \\
\text { fora do fogão, os materiais de limpeza não devem ficar ao } \\
\text { alcance dos bebês, entre outras, e outra era alguns erros no } \\
\text { trânsito, como: uso de celular dirigindo, não atravessar na } \\
\text { faixa de pedestre, crianças no banco da frente, entre outras. }\end{array}$ \\
\hline 4 & $\begin{array}{l}\text { Conhecendo } \\
\text { o alfabeto }\end{array}$ & $\begin{array}{l}\text { Instigar o } \\
\text { conhecimen } \\
\text { to das } \\
\text { crianças a } \\
\text { respeito do } \\
\text { alfabeto }\end{array}$ & $\begin{array}{l}\text { Acadêmicas, pais } \mathrm{e} \\
\text { crianças. }\end{array}$ & $\begin{array}{l}\text { O jogo nomeado "Brincando com as letrinhas" foi } \\
\text { confeccionado com papel colorido onde cada papel } \\
\text { continha letras e desenhos os quais as crianças deveriam } \\
\text { associar a letra do alfabeto com a primeira letra do } \\
\text { desenho, esse método de brincadeira foi com crianças mais } \\
\text { jovens. As crianças mais maduras o jogo foi adaptado da } \\
\text { seguinte forma: foi feito um sorteio de palavras e a criança } \\
\text { tinha que montar uma frase que tivesse sentido e coerência } \\
\text { com as palavras sorteadas. }\end{array}$ \\
\hline 5 & $\begin{array}{l}\text { Histórias } \\
\text { contadas: } \\
\text { jeca tatu }\end{array}$ & $\begin{array}{l}\text { Educação } \\
\text { em Saúde } \\
\text { sobre } \\
\text { Verminoses }\end{array}$ & $\begin{array}{l}\text { Acadêmicas, pais e } \\
\text { crianças. }\end{array}$ & $\begin{array}{l}\text { A história foi contada de forma lúdica, cada menina sendo } \\
\text { um personagem da história ia atuando até chegarmos na } \\
\text { reflexão final. As crianças se mostraram atenciosas o tempo } \\
\text { inteiro e interagiram, fazendo perguntas e se mostrando } \\
\text { interessadas. Aos pais, foi entregue um folheto informativo } \\
\text { contendo as principais verminoses, suas causas e sua } \\
\text { prevenção. }\end{array}$ \\
\hline 6 & Boas ações & $\begin{array}{l}\text { Contribuir } \\
\text { para a } \\
\text { inserção na } \\
\text { sociedade } \\
\text { através da } \\
\text { convivência } \\
\text { social e } \\
\text { boas } \\
\text { maneiras. } \\
\end{array}$ & $\begin{array}{l}\text { Acadêmicas, pais } \mathrm{e} \\
\text { crianças. }\end{array}$ & $\begin{array}{l}\text { Inicialmente, tivemos um momento de interação com o } \\
\text { tema, onde cada participante falava o seu nome e em } \\
\text { seguida, uma palavra de gentileza. No segundo momento, } \\
\text { cantamos uma música que falava a importância das } \\
\text { palavrinhas mágicas. Em seguida, fizemos uma roda de } \\
\text { conversa onde cada criança opinava sobre o uso das } \\
\text { "palavrinhas mágicas" e sua importância. Para finalizar, } \\
\text { houve um momento de pintura, onde os desenhos } \\
\text { retratavam situações de gentileza. }\end{array}$ \\
\hline 7 & $\begin{array}{l}\text { Musicoterap } \\
\text { ia }\end{array}$ & $\begin{array}{l}\text { Promover } \\
\text { um } \\
\text { momento de } \\
\text { bem-estar } \\
\text { com as } \\
\text { crianças em } \\
\text { internação } \\
\text { hospitalar. }\end{array}$ & $\begin{array}{l}\text { Acadêmicas, pais, } \\
\text { crianças, profissionais e } \\
\text { músicos. }\end{array}$ & $\begin{array}{l}\text { As acadêmicas e os músicos estavam fantasiados; } \\
\text { inicialmente, nos apresentamos para as crianças e cantamos } \\
\text { músicas infantis. A participação delas variava de acordo } \\
\text { com a música, então pedimos para que elas escolhessem a } \\
\text { música e a interação foi melhor. Cantamos por toda a } \\
\text { enfermaria, e para finalizar a ação, agradecemos aos } \\
\text { profissionais pela acolhida e oportunidade de realizar as } \\
\text { intervenções. }\end{array}$ \\
\hline
\end{tabular}




\section{Discussão}

O processo de adoecimento caracteriza-se como um fator promotor de estresse e desconforto físico e afetivo na vida dos indivíduos, uma vez que este, favorece o distanciamento do contexto familiar e ingresso no ambiente hospitalar. Esse acontecimento, contribui para a mudança de rotina do paciente adoecido, submetendo-o a dietas alimentares, restrição de contato com familiares ou colegas, avaliação do estado do indivíduo com aparelhos desconhecidos e mudanças nos horários de descanso, ocasionando a ruptura de vínculos afetivos, sentimento de perda de privacidade e incapacidade sobre o próprio corpo.

Ao trazer essa avaliação para o contexto infantil, percebe-se que esse acontecimento poderá ocasionar uma lembrança estressante e traumática para a criança, associando o hospital ao sentimento de dor, desconforto e privação, bem como, desenvolver sentimentos ansiosos e depressivos. Em concordância com esta avaliação, estão os estudos de Rocha; Rocha (2018) e Chesani (2019) destacando a necessidade de avaliar a criança de forma integral, dando ênfase a sua saúde mental e bem-estar.

Segundo a Lei n ${ }^{\circ}$ 8.080, de 19 de setembro de 1990, que dispõe sobre as condições para a promoção, a proteção e a recuperação da saúde a organização e funcionamento dos serviços correspondentes e dá outras providências, no parágrafo único, inciso VIII, garante a continuidade das atividades escolares, bem como o estímulo à recreação, em casos de internação de criança ou adolescente (Brasil, 2015). Assim, visando o cumprimento dessa lei, o ambiente foco do estudo, ofertava área de lazer, para distração infantil e melhor adaptação ao novo ambiente, bem como, ações de educação em saúde para as mães e profissionais, permitindo melhor imersão no ambiente e a criação de vínculos de segurança entre pais e profissionais.

Dessa forma, ao realizar a primeira ação sobre higiene e autocuidado observou-se a eficácia da atividade, visto que, as crianças foram incentivadas a cuidar do seu corpo, proporcionando autonomia e despertando sensações de prazer, bem como, reduzir o risco de doenças. Com isso, conforme aprendiam, permitiam-se uma maior interação com as outras crianças e com os profissionais das diversas áreas da saúde, proporcionando adesão e aceitação do tratamento.

O brincar é um importante recurso mediador para as crianças hospitalizadas, favorecendo o fortalecimento do vínculo entre a criança e a equipe de saúde, bem como contribui no aprendizado, na execução de ações e na multiplicação do conhecimento, atenuando a ociosidade, a ansiedade e sentimentos depressivos e temerosos, transformando o ambiente hospitalar em um local mais acolhedor e divertido (Oliveira, 2017).

Assim, durante a atividade sobre alimentação saudável, as crianças e os acompanhantes demonstraram conhecimento sobre a importância de alimentos saudáveis presente na alimentação infantil, bem como, a importância de ofertar a criança a mesma alimentação familiar. Com isso, destacou-se a preferência por alimentos naturais, como frutas, leguminosas e verduras, propiciando um crescimento satisfatório e peso adequado. Diante disso, salienta-se que uma alimentação responsiva e efetiva estimula a ingestão de alimentos de forma paciente, esperando a criança parar de comer para averiguar sinais de saciedade, possibilitando a autonomia da criança para que ela conheça e deguste esses alimentos (Modes, Gaíva \& Monteschio, 2020).

De acordo com os estudos de Alves (2019) e Freire (2019), destacam-se a necessidade de orientar sobre a alimentação saudável em crianças, devido a prevalência de comorbidades nesta faixa etária. Assim, uma alimentação de qualidade é fundamental tanto para o crescimento quanto para a aprendizagem infantil, no entanto, a adoção de alimentos industrializados pode desencadear problemas de saúde, dentre eles diabetes mellitus, hipertensão e obesidade. Discutiu-se rapidamente sobre estas patologias, e as genitoras demonstraram conhecimento acerca do assunto e disposição para adotar uma alimentação mais saudável para os filhos, como forma de prevenção.

Conforme Buscaratto (2020), a contação de história no público infantil é utilizada como recurso terapêutico, pois estimula a imaginação, desperta sentimentos de paz, alegria e conforta a criança, auxiliando no enfrentamento de suas emoções e atenuando o sofrimento. Destarte, realizou-se uma oficina de educação em saúde sobre verminoses através da contação de 
histórias, para facilitar o aprendizado e estimular a prevenção. Em vista disso, e com o objetivo de melhorar a adesão e compreensão do público infantil, foi utilizado uma versão adaptada sobre a história do "Jeca Tatu". Através dessa metodologia, observou-se que o público do estudo adotava esses hábitos rotineiros, favorecendo a contaminação por esses parasitas, bem como, permitiu uma melhor compreensão do público infantil, visto que referiram não desejar parecer com o personagem.

Ao avaliar as pesquisas de Sucasas (2018), constatou-se que as verminoses ou infecções parasitárias afetam principalmente o público infantil, prejudicando no desenvolvimento cognitivo e ponderal, sendo desencadeado por hábito de andar descalço, de higiene inadequada das mãos antes das refeições e pela a presença de animal doméstico nas residências. Diante disso, destaca-se que as mães e/ou responsáveis relataram sobre algum familiar que já foi contaminado. Com isso, enfatizou-se a lavagem das mãos antes e após as refeições, após sair do banheiro, após pegar no animal de estimação e após brincar, assim como, a não recomendação de andar descalço. Para facilitar essas estratégias de prevenção utilizou-se o recurso da musicoterapia, através da canção "lava as mãos" da Galinha Pintadinha, proporcionado um ambiente descontraído e alegre, o que contribuiu para o aprendizado infantil através das brincadeiras.

Sabe-se que o ambiente hospitalar proporciona na criança sentimentos de privação e perdas, dentre elas, o afastamento da rotina escolar e dos colegas de sala, intensificando a angústia e a tristeza. A fim de atenuar esses sentimentos e contribuir para adesão ao tratamento foi elaborada a atividade conhecendo o alfabeto através de um jogo lúdico. Conforme estabelecido por Santos, (2017), a ludoterapia utiliza a brincadeira para estabelecer uma conexão entre a realidade e o imaginário, permitindo que a criança desenvolva raciocínio, curiosidade, bem como contribua para melhora do desenvolvimento, redução da ansiedade, ociosidade e possibilite a interação com as outras crianças e o estreitamento de vínculos entre paciente, pais e profissionais, tornando o ambiente hospitalar um local mais prazeroso.

Após o desenvolvimento da atividade percebeu-se que as crianças tinham conhecimento escolar adequado, com isso, foram elaboradas frases com algumas figuras que foram selecionadas o que estimulou o raciocínio da criança ao mesmo tempo que brincavam. Assim, nota-se que o valor terapêutico do ensinar associado ao lúdico, favorece o restabelecimento físico e emocional, possibilitando melhor adaptação no processo de hospitalização, favorecendo a cooperação no tratamento e tornando-o menos traumatizante, assim como, fornece melhores condições para a recuperação e possibilita a construção de vínculos entre paciente, família e profissional de saúde (Carvalho et. al, 2019).

É notório que o corpo adoecido passa por várias mudanças, e quando associadas ao ambiente hospitalar os sentimentos de desconforto, ansiedade e irritabilidade são intensificados, principalmente no público infantil. Ao avaliar esta situação, percebeu-se a necessidade de trabalhar as ações de boas maneiras com os pacientes da pediatria, visto que, representa um ambiente estressante, tanto para criança, quanto para os pais e os profissionais. Enfatizou-se sobre as "palavras mágicas", mostrando o caráter positivo da metodologia e incentivando a prática dessas ações, tornando o público infantil multiplicador desse conhecimento e permitindo a compreensão sobre as contribuições dessa prática no convívio em sociedade. Segundo Meira (2017), é necessário ensinar e reforçar a criança a praticar cotidianamente certos valores presentes para o bom convívio em sociedade.

Segundo a Organização Panamericana de Saúde (2018), as lesões ocorridas no trânsito são a principal causa de morte entre crianças e jovens de 5 a 29 anos. Em divergência com essa afirmação, avaliou-se as pesquisas de Azevedo (2017), que constatou a faixa etária de um a dois anos, com uma predominância de ocorrências de acidentes. Assim, entende-se que as crianças por ainda não possuírem desenvolvimento cognitivo completo, necessitam da vigilância de um responsável.

Em vista disso, foi elaborada uma atividade de educação e saúde para os cuidadores a fim de prevenir acidentes domésticos e no trânsito, trazendo situações do dia a dia para serem discutidas e orientadas às crianças sobre esses acidentes e maneiras de evitá-los através de um jogo lúdico de Sete Erros. Ao trazer essa realidade ao local de estudo, percebeu-se a 
concordância com as pesquisas anteriores, em que as mães relatavam evitar que os filhos menores entrem na cozinha, que fiquem longe de tomadas e sejam supervisionados continuamente.

Considerando que o ambiente hospitalar desperta desconforto, ansiedade e ociosidade nas crianças, desenvolveu-se no último encontro a atividade de musicoterapia, afim de atenuar o sofrimento a partir do espaço lúdico, auxiliar na recuperação física, expressão emocional e aumento de autoestima. Diante disso, percebeu-se o caráter benéfico da mesma, tornando o ambiente hospitalar menos estressante, bem como proporcionou às crianças e mães sentimentos de bem-estar, calma e relaxamento. Além disso, despertou nos pacientes da pediatria sentimentos de esperança e alegria, passando a expressar maior aceitação ao tratamento e o desejo de retornarem para casa (Freire et. al, 2018).

Diante disso, conclui-se que as atividades de ludoterapia apresentaram-se satisfatórias, pois favoreceram uma comunicação efetiva, a formação de vínculo entre profissional-paciente e possibilitou o cuidado integral e humanizado. As ações atenuaram sentimentos de estresse, medo e ansiedade, dando origem a um novo ambiente e novas experiências, o que contribuiu com o desenvolvimento cognitivo e social, além de despertar sentimentos de esperança e bem-estar (Gesteira et. al, 2020).

\section{Conclusão}

As intervenções realizadas promoveram um impacto positivo no convívio hospitalar entre as crianças, com profissionais, familiares e estudantes. Constatou-se através da participação ativa das crianças e empolgação em cada ação, bem como a demonstração de afeto dos os pais ou acompanhantes durante as atividades, pois percebiam a melhora do quadro clínico de seus filhos e a empolgação que demonstravam.

A vivência proporcionou uma visão além da teoria, agregando valores na formação acadêmica sobre a relevância da assistência holística e humanizada que deve ser trabalhada com o paciente, em especial o infantil. Outrossim, ressalta-se a relevância do desenvolvimento de atividades lúdicas ou métodos inovadores com este público, visto que, trata-se de uma população vulnerável que necessita de uma atenção e respeito maior para manter sua saúde, costumes diários e estímulo a sua criatividade para o desenvolvimento infantil, além da promoção do bem-estar durante a internação hospitalar.

Portanto, os acadêmicos perceberam a importância de fortalecer o vínculo entre profissional e paciente, pois favorece sentimentos de confiança e melhor adesão ao tratamento. Com isso, contribuiu de maneira eficaz, proporcionando o aprendizado teórico-prático, a fim de construir profissionais capacitados e humanizados, bem como contribuiu para a melhor assistência ofertada ao paciente pediátrico hospitalizado. Contudo, estimula-se a prática de ações desta natureza no ambiente hospitalar, a fim de contribuir para um melhor prognóstico dos pacientes.

O desenvolvimento de novas práticas de promoção da saúde impede que a criança seja reduzida a perspectiva do risco e do adoecimento. Desse modo, sugere-se a realização de novos estudos voltados a promoção da saúde de crianças hospitalizadas, visto que tal público se torna mais vulnerável em tais condições, sendo necessária uma compreensão mais subjetiva de suas condições de saúde.

\section{Referências}

Alves, E. (2019). Promoção da Alimentação Saudável na Prevenção da Obesidade em Crianças do $2^{\circ}$ ano do $1^{\circ}$ ciclo do Ensino Básico (Mestrado) - Escola Superior de Enfermagem de Lisboa, 01-157 f.

Azevedo, A. V. S., Lançoni Júnior, A. C., Crepaldi, M. A., et al. (2017). Interação equipe de enfermagem, família, e criança hospitalizada: revisão integrativa. Revista Ciência \& Saúde Coletiva. 22, (11), 3653-3666.

Barroso, M. C. C. S., Santos, R. S. F. V., Santos, A. E. V., Nunes, M. D. R., Lucas, E. A. J. C. F. (2020). Percepção das crianças acerca da punção venosa por meio do brinquedo terapêutico. Acta Paulista de Enfermagem. 33. 
Berté, C., Ogradowski, K. R., Zagonel, I. P., Tonin, L., Favero, L., Junior, R. L. (2017). Brinquedo terapêutico no contexto da emergência pediátrica. Rev Baiana Enferm. 31(3), 20378.

Buscaratto, C. E. (2020). Contação de História como Forma Terapêutica na Recuperação de Crianças e Adolescentes de um Hospital de Santa Catarina. Revista de Extensão da UNIVASF - Petrolina. 08, (01), 100-112.

Carvalho, M. C. (2019). O Lúdico na Hospitalização Pediátrica. Monografia (Especialista). 01-39 f. https://www.arca.fiocruz.br/handle/icict/37302

Catapan, S. C., Oliveira, W. F., Rotta, T. M. (2019). Palhaçoterapia em ambiente hospitalar: uma revisão de literatura. Ciência \& Saúde Coletiva. 24(9), 34173429 .

Chesani, F. H., et al. (2019). O acolhimento ao cuidador de crianças internadas. Revista Psicologia, Diversidade e Saúde. 8, (2), 217-228.

Freire, S. G. B., et al. (2019). Aprendizagem e Desenvolvimento: Um Estudo sobre recomendações alimentares para a criança na Educação Infantil. Id Online Revisa Multidisciplinar e de psicologia. 13, (45), 11-20.

Gerhardt, T. E., Silveira, D. T. (2009). Métodos de Pesquisa. Editora da UFRGS.

Gesteira, E. C. R., et al. (2020). Projeto lúdico para crianças hospitalizadas: um relato de experiência. Revista Eletrônica Acervo Saúde. 12, (4953), 01-06.

Meira, M. M., et al. (2017). O papel da pessoa na formação dos valores sociais das crianças. Revista Even. Pedagógica. 8, (2), 22, 897-913.

Modes, P. S. S. A., Gaíva, M. A. M., Monteschio, C. A. C. (2020). Incentivo e Promoção da Alimentação Complementar Saudável na Consulta de Enfermagem à Criança. Revista Contexto \& Saúde. 20, (40), 189-198.

Oliveira, R. L. B. (2017). Atividades Lúdicas como estratégia para a promoção da saúde bucal nas crianças e adolescentes hospitalizados. I Seminário de humanização do HUPAA. 1, (4), 33-38.

Oliveira, W. F., (2016). O núcleo de humanização, arte e saúde: uma experiência coletiva de produção social de saúde. Cadernos Brasileiros de Saúde Mental. $8,(18), 198-211$.

OMS (1990). lei № 8.080, De 19 De Setembro De 1990. http://www.planalto.gov.br/ccivil_03/leis/18080.htm

Organização Panamericana De Saúde. Folha Informativa - Acidentes De Trânsito. https://www.paho.org/bra/index.php?option=com_content\&view=article\& id=5147: acidentes-de-transito-folha-informativa\&itemid=779

Pereira, A. S., et al. (2018). Metodologia da pesquisa científica. UFSM. Obtido em: https://repositorio.ufsm.br/bitstream/handle /1/15824/L ic_Co mputacao_Metodologia-Pesquisa-Cientifica.pdf?sequence=1.

Reis, M. R. P., Freire, M. H., et al. (2018). A canção de apresentação como um recurso de musicoterapia na saúde mental. Revista In Cantare. 9, (1), 1-108.

Rocha, E. N. T., Rocha, R. R., et al. (2018). O tratamento de crianças hospitalizadas. Journal of Specialist. 2, (2), 4.

Sabino, A. S. S., Esteves, A. V. F., Oliveira, A. P. P., Silva, M. V. G. (2018). O conhecimento dos pais quanto ao processo do cuidar por meio do brincar. Cogitare Enferm. 23, (2), 52849.

Santa Casa De Misericórdia De Sobral. (2012). Serviço: Pediatria, Sobral, 30 de abr. de 2012. https://www.stacasa.com.br/servicos/

Santos, C. S., et al. (2017). Humanização no tratamento de crianças com câncer através das atividades lúdicas. International nursing congress. 1, (1), 01-03.

Silva, S. G. T., et al. (2017). Influência do Brinquedo Terapêutico na ansiedade de crianças escolares hospitalizadas: Ensaio clínico. Revista Brasileira de Enfermagem. 70, (6), 1244-1249.

Sucasas, H. T. F., et al. (2018). Avaliação parasitológicas em crianças em crianças do projeto novo horizonte no município de Manhuaçu, Minas Gerais. IV Seminário Científico da FACIG. 1, (1), 1-8. 